\title{
Cooperation in $R \& D$ as a Leading Indicator of Innovative Activity Growth
}

Submitted 10/08/19, $1^{\text {st }}$ revision 11/09/19, $2^{\text {nd }}$ revision 17/10/19, accepted $24 / 11 / 19$

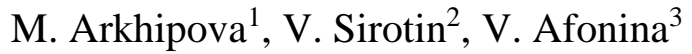 \\ Abstract:
}

Purpose: The article is focused on new trends in cooperation activity in research and development in the manufacturing industries of Russia. Various types of cooperation are considered, special attention is paid to research organizations and universities.

Design/Methodology/Approach: In the context of this issue, it seems necessary to consider the conceptual framework and information basis for the analysis of scientific activity, to study the problems of scientific and technical cooperation, based on the works of foreign and domestic scientists and to develop indicators of cooperative activities.

Finding: Authors proposed to rank the regions of Russia by the level of cooperation activity based on a specially developed hidden indicator. Comparison of the results obtained with regional layers of the costs of $R \& D$ suggests that joint research and development activities are typical for those regions that pay considerable attention to development of science. Ranking regions of Russia in terms of cooperative activity allowed identifying the leaders and outsiders of this process.

Practical implications: The results of the study can be used in the development of measures of regional development of the country in the implementation of $R \& D$.

Originality/Value: To study the impact of the resource base on the cooperative activities of the organization, the authors proposed a composite indicator that includes a wide range of indicators that consider various aspects of cooperative activity.

Keywords: Latent indicator, principal component analysis, propensity to cooperation, processing industries, mixture of probability distributions, parametric classification.

JEL code: $C 43,123,033$.

Paper type: Research article: Innovation, Research and Development.

Acknowledgement: This work was supported by a grant of Russian Foundation for Basic Research №18-010-00564 Modern Tendencies and Social and Economic Consequences of Digital Technologies Development in Russia.

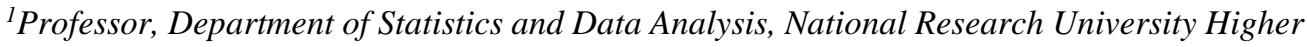
School of Economics, Moscow, Russian Federation, mahipova@hse.ru

${ }^{2}$ Professor, Department of Statistics and Data Analysis, National Research University Higher School of Economics, vsirotin@hse.ru

${ }^{3}$ Associate Professor, Department of Management, Odintsovo Branch of MGIMO University, Moscow, Afonina_Vera@mail.ru
} 


\section{Introduction}

The experience of the most developed countries shows that technological development is provided by several conditions, the main of which are the accumulated scientific and technical potential, institutional factors of technological progress, as well as the presence of large science-intensive corporations. The intensive interaction with organizations carrying new knowledge and possessing additional competencies in relation to this organization is becoming increasingly important in the innovation process.

In a difficult economic situation, both in the global and national-regional markets, many enterprises and organizations face several problems. Among them, a special place is taken by the lack of resources, both financial and human, without which it is impossible to produce competitive products based on innovation, as well as the increasing complexity of the modern technological base, which requires more competence and additional knowledge from enterprises in related technological fields. In this regard, scientific and technical cooperation, in which organizations enter close innovation cooperation, combining efforts, resources, and thereby minimizing possible risks and reducing costs associated with the creation and implementation of innovations is the way to solve this problem. Moreover, innovation cooperation often occurs at the junction of different sectors of the economy, contributing to the integration of scientific and technical knowledge from different fields.

Cooperation activity in research and development (R\&D) can be used to assess the competitiveness of various activities in terms of different productions' technological efficiency. If there is a simultaneous increase in the interest of Russian and foreign partners in any kind of activity, it may indicate its competitiveness. The interest of only Russian partners in cooperation shows the internal competitiveness of products, goods or services for the Russian market. On the other hand, the low competitiveness of the activity can be evidenced by the decline in interest in cooperation from both foreign and Russian partners. Therefore, the study of scientific and technical cooperation in different economic activities is the most effective to identify possible points of economic growth, which are formed at the junction of several sectors of the economy and areas of knowledge.

It is generally accepted that the scale and intensity of cooperation processes in innovation activities are directly related to the need to reduce the risk in research and development for new technological products. If this statement is true, the propensity to cooperate and its scale depend on the type of activity of manufacturing industries. As the degree of technological effectiveness increases, the tendency of enterprises to cooperate increases. The general pattern is that the shorter the production cycle and (or) more complex the production technology, the greater the desire for cooperation. We are going to test this statement using data on cooperation in manufacturing activities of different technological level. From this perspective, cooperation in R\&D can be used to diagnose points of growth of innovation and technological development. 
The study of cooperation relations by types of partners is also of considerable interest. Here we will be primarily interested in partnerships in conducting R\&D with scientific organizations, universities and other higher education institutions. In Russia, for a long period, the main partners in scientific and technical cooperation were suppliers of equipment, materials, components or software. Has this trend continued in Russia? the increased role of universities in cooperative activity?

Another important area of research is the sustainable dynamic regional development. In the regions with the most favorable climate for doing business, companies and entrepreneurs, as well as highly skilled labor force are attracted to invest their capital profitably. As a result, regions tend to organize the most effective political, legislative, economic, environmental and cultural system. The success of the regions in this determines their strength and competitiveness.

Russian regions are heterogeneous in terms of regional development due to the natural, geographical, demographic, socio-economic characteristics of each subject. We can use the peculiarities of the regions for the successful progressive development of each of them. In this regard, it is interesting to find out whether the promotion of research and development has an impact on cooperation activities of regions, and which regions of Russia are the most attractive for national and foreign partners.

\section{The Conceptual Framework}

Traditionally, two forms of international interaction are distinguished: cooperation and collaboration. Cooperation is the joint work of two or more organizations, the development of joint plans and their implementation. Work in cooperation is divided into several parts, each of which is performed by a certain group in each sequence. Each organization remembers its interests and boundaries, fulfilling its obligations to achieve a common goal. Thus, the sum of all separately executed operations will be the result of cooperation.

In collaboration, all knowledge, resources and capacities become common, and the participants unite their capital. All participants simultaneously participate in the process. Organizations negotiate interests and actions to create a synergistic effect, distribute financial responsibility to achieve the best result, which is not under the power of one individual company (Utami and Ferdiansah, 2017). Participants have no direct influence on each other but share control and responsibility for the future result among themselves. With this type of interaction, the result is more than the sum of all the tasks performed, because all the participants work together.

Innovation cooperation is a participation in joint innovation projects, research and development. Partners in cooperation can be enterprises, research institutes, educational institutions, non-profit and commercial organizations. It is innovation cooperation, that is, cooperation, has the highest potential, as it contributes to the 
scientific and technical development of each member of the partner group of the enterprise - an active participant in joint innovation projects. Cooperation participants have access to knowledge and technology that would otherwise be inaccessible to them. Cooperation in conducting $\mathrm{R} \& \mathrm{D}$, in the first place, should provide:

- Orientation of part of fundamental and applied research on the needs of the market (development of generic technologies).

- Financial support of applied R\&D by the market and the state.

- Close cooperation between industry and research sector in conducting R\&D.

However, cooperation between business and research organizations despite the significant growth potential has not yet received proper development. This can be explained by the fact that business does not tend to focus on the direct use of the results of basic science, because it requires significant time and human resources. In addition, the ineffectiveness of intellectual property protection can be a serious obstacle on the part of business to enter cooperative relations with the R\&D sector, which jeopardizes the right of the firm to develop products and technologies. For their part, research organizations engaged in basic science are more inclined to conduct long-term research aimed at obtaining new knowledge than to apply in practice the results already obtained. Nevertheless, the benefits of cooperation and often the inability to develop innovations independently are an important incentive for business to cooperate in conducting $\mathrm{R} \& \mathrm{D}$.

Innovation cooperation can take many forms. Among them is horizontal cooperation, when the interaction between consumers and suppliers is based on supply chains. Cooperation can take place in the framework of joint participation with other enterprises or government research organizations (Gamidullaeva, 2018).

There are internal (national) cooperation that acts within the country and external cooperation with foreign partners. Within Russia, an example of internal cooperation can serve as scientific and technological cooperation between research organizations, universities, the business sector, industry in various combinations. An example is the National Research University Higher School of Economics (HSE), which cooperates, on the one hand, with institutions of the Russian Academy of Sciences and as one of the results has 1042 joint publications, on the other hand, it cooperates with leading universities such as Moscow State University, MIPT university (346 and 246 joint publications correspondently) and others.

At the same time, HSE is actively cooperating with foreign partner universities, which in turn is an example of international (external) cooperation. For example, HSE collaborates in research with partners such as the University of Florida (66 joint publications), University of London (99 joint publications), Harvard University (61 joint publications), MIT (61 joint publications), etc. Numbers of joint publications during the period from 1980 to 2016 year with each of the mentioned universities are $66,99,61,71$ correspondently. Cooperation is also studied on countries and regions 
of the location of cooperation partners, types of cooperation ties and partners. In the study of cooperation on location of countries or regions they usually consider following types of location: Russia; CIS; EU; EU candidate countries; Liechtenstein; Norway; Switzerland; USA; Canada; India; China and other countries.

As types of cooperation relations, they commonly use permanent cooperation (with the participation of regular partners); cooperation within the framework of a specific project; occasional (informal) cooperation (not related to a special project). By types of partners cooperation is divided into the following categories: organizations within the group, which includes the organization; consumers of goods, works and services; suppliers of equipment, materials, components, software; competitors in the industry; consulting, information firms; scientific organizations; educational organizations of higher education.

Such organization of observation allows to obtain data on cooperation in two main aspects: types of partners of innovative cooperation with respect to their geographical location and types of partners with respect to the type of cooperative relations involved. The study of cooperative relations in Russia in various aspects is possible on the basis of statistical form No 4 - innovation "Information about the innovative activity of the organization", which provides statistical data that allow to study cooperative relations and cooperation of organizations in the scientific and technical sphere.

\section{Literature Review}

The problem of scientific and technological cooperation at different levels of hierarchy (external, internal) is reflected in many works of both foreign and domestic scientists. The development of improved measures aimed at the development of national innovation systems is given special attention in the OECD's cross-country annual studies, e.g. (OECD, 2018). The hypothesis of the need to consider the institutional and economic national characteristics of the indicators of cooperation in their impact on innovation activity is substantiated (Nagimov et al., 2018). A holistic and innovative framework is proposed for policy formulation and collaboration tools for the fruitful development of different countries in a way that aligns cross-country differences and leaves no one behind (the report proposes a holistic and innovative framework to shape and guide development co-operation policies and tools that are fit for the purpose of leaving no one behind). Studies show that countries of the world have a different propensity to cooperate, which is largely determined by the national characteristics and the level of development of the country.

The publications of the Organization for economic cooperation and development (OECD, 2014) provide a detailed analysis and classification of technological cooperation on the goals and issues of cooperation. It is hypothesized that cooperation and partnership contribute to the development of new markets, as well as to the 
reduction of costs through joint production, which affects the innovation activity of these firms. As a result of the factor analysis of various cooperative associations in more than 30 countries of the world, the most important factors of cooperation for the propensity to innovation were identified, and then on the basis of the selected features, a multistage classification of cooperative associations was proposed. The most influential factors of cooperation on the propensity to innovation were attributed to the time period of cooperation, the scale and type of management, organizational forms of cooperation participants, and the type of financing of cooperation.

Geisler (1995) offers a well-grounded theoretical basis for scientific and technical cooperation based on congruence (proportionality) of existing theories of interorganizational relations. The theory is based on the empirical experience of industry-University type cooperation in the USA. The paper deals with two research questions: 1) Why universities and industrial companies are involved in cooperation in the field of research and development? 2) what factors influence their survival? Hypothetical dependence on resources is assumed as an incentive to initiate joint R\&D.

Geisler (1997) lists three general and two particular myths for each type of so-called cross-sectoral technological cooperation: University, industry, Universitygovernment, and industry-government. These myths simplify the reasons for the success or failure of technological cooperation. The article concludes that crosssectoral cooperation is real and gives certain results that benefit all cooperating parties. However, cooperation is a complex phenomenon that cannot and should not be reduced to simplified statements, usually based on myths about its feasibility.

The paper by Ramani (2000) presents a game-theoretic model of technological cooperation in which a developing country firm can either develop innovations on its own, or acquire information, or cooperate with a developed country firm. Technological cooperation changes the likelihood of commercialization success.

The Russian literature also raises the question of the influence of cooperation as a fundamental factor on the propensity to create innovations (Kozlov, Sokolov and Yudaeva, 2004). The hypothesis of cooperation influence on innovative activity of Russian enterprises is put forward. To carry out the regression analysis as the main model, the authors selected the Probit regression with an indicator of various types of innovation as a dependent variable. As a result of the study, the main barrier to innovation activity of Russian enterprises was recognized as the lack of individual enterprises' own funds, as well as limited access to external financing. A possible option to overcome this barrier is proposed technological cooperation.

Arkhipova and Golichenko (2007) investigate the state of cooperation in innovative activity in Russia and considers the tendencies of its development at macro - and meso - levels. In the context of Russian realities, the hypothesis of the decline in the scale and propensity to cooperate with the decrease in the degree of technological 
production is rejected. These indicators are higher in medium-tech activities than in high-tech ones. Among the main factors that encourage enterprises to resort cooperation the authors include:

$>$ The increasing complexity of the technological base which requires additional skills and knowledge.

$>$ The acceleration of technological cycles.

$>$ The growth of cost and increased risks of innovation.

The paper concludes that the development of partnership and cooperation contributes to the compensation of the natural risk of innovation and acts as a factor in increasing the innovation activity of the business environment. Thus, there is an extensive theoretical and practical base of research of scientific and technical cooperation, the factors that have the greatest impact on its development are proposed.

The share of organizations involved in scientific and technical cooperation remains relatively low in the total number of operating organizations engaged in technological innovation, and since 2010 has been steadily decreasing, but exceeds the share of enterprises passively acquiring technologies. This fact may indicate a greater propensity of Russian organizations to cooperate and cooperate in order to achieve competitive advantages in the market than to simply exchange technological knowledge.

A significant share of joint projects for the implementation of $R \& D$ falls on the organizations that implemented technological innovations (Gumpert, 2019). In general, in Russia this figure in 2016 amounted to $79.4 \%$, for organizations that did not implement technological innovations is only $20.5 \%$. The main share of Russian organizations is focused on the implementation of joint projects with Russian partners, which indicates the orientation of Russian enterprises in the production of goods and services to take place on the domestic market. This fact can be largely explained by the fact that the domestic market is characterized by a low level of demands of the Russian consumer to the quality of the product (goods, services), at the same time it is quite capacious.

Sanctions from different countries to some extent play into the hands of many businesses, creating market niches through the introduction of counter sanctions on imported goods. These formed niches also hurry to fill many enterprises, without complicating themselves with creation of the high-risk hi-tech production competitive in the international arena. According to Russian Federal State Statistics Service (2016), $94.3 \%$ of organizations involved in joint projects are focused on Russian partners. Partners from CIS countries account for $5.7 \%$ (in 2015, the value of this indicator was $6.5 \%), 13.8 \%$ of organizations cooperate with partners from the EU, Iceland, Liechtenstein, Norway, Switzerland, 2.3\% - with partners from the US and Canada (against $4.3 \%$ in 2015). The activity of cooperation relations with partners from India 
and China, as well as other countries remained unchanged at $4.6 \%$ and $6.0 \%$, respectively.

If we consider the types of economic activities of manufacturing industries (MI), the tendency of organizations to cooperate decreases according to the decrease in the degree of technological production (Table 1).

Table 1. The share of manufacturing organizations that participated in joint projects and implemented technological innovations in 2015-2016, \% (GKS, 2016)

\begin{tabular}{|l|l|l|}
\hline \multirow{2}{*}{$\begin{array}{l}\text { Types of activity of manufacturing } \\
\text { industries on the technological level }\end{array}$} & $\begin{array}{l}\text { Specific weight of the organizations } \\
\text { participating in joint projects and carrying } \\
\text { out technological innovations }\end{array}$ \\
\cline { 2 - 3 } & 2015 & 2016 \\
\hline Manufacturing (total) & $\mathbf{3 3 . 0}$ & $\mathbf{2 9 . 9}$ \\
\hline High-technology & 49.6 & 46.4 \\
\hline High-level medium-tech & 34.3 & 30.1 \\
\hline Low-level medium-technology & 31.7 & 29.2 \\
\hline Low-tech & 12.7 & 11.5 \\
\hline
\end{tabular}

It should be noted that there is a decrease in cooperation activity in almost all types of production activities. Some growth of cooperation activity of foreign partners is noted in the types of activities to produce electric machines and equipment and the production of cars, trailers and semi-trailers included in the medium-technical production of high level. High cooperative activity of organizations of high-tech industries provides a type of activity (TA) production of aircraft, including space. $62.3 \%$ of organizations of this type of activity participated in joint projects on implementation of $\mathrm{R} \& \mathrm{D}$, further $53.3 \%$ follows production of electronic components, the equipment for radio, television and communication.

Among the medium-tech types of low-level production, it should be noted Metallurgical production, in which $50.0 \%$ of organizations participated in joint projects for the implementation of $\mathrm{R} \& \mathrm{D}$, as well as the construction and repair of ships by $42.9 \%$.

As for cooperation with foreign partners, whose interest in cooperation indicates the global competitiveness of the activity, there is a reverse trend (Table 2). The highest cooperative activity is manifested in low - tech industries, and the lowest-in high-tech. Thus, the share of high-tech production organizations cooperating with foreign partners from the EU, Iceland, Liechtenstein, Norway, Switzerland is 5.1\%, in hightech medium $20.9 \%$, in low-tech medium $17.8 \%$, in low $28.6 \%$. This is not a favorable trend for Russia. However, under certain conditions, it can be used for domestic technological breakthrough to create competitive products in global international markets on its own. 
Table 2. The share of manufacturing organizations involved in joint projects and implementing technological innovations in 2015-2016 by countries and regions of the partners ' location, \% (GKS, 2016)

\begin{tabular}{|l|l|l|l|l|l|}
\hline $\begin{array}{l}\text { Types of activity of } \\
\text { manufacturing } \\
\text { industries on the } \\
\text { technological level }\end{array}$ & Russia & CIS & EU & $\begin{array}{l}\text { USA and } \\
\text { Canada }\end{array}$ & $\begin{array}{l}\text { India and } \\
\text { China }\end{array}$ \\
\hline Manufacturing (total) & 93.8 & 6.4 & 14.5 & 2.7 & 4.9 \\
\hline High-technology & 97.7 & 5.1 & 5.1 & 2.3 & 2.9 \\
\hline $\begin{array}{l}\text { High-level medium- } \\
\text { tech }\end{array}$ & 91.1 & 7.6 & 20.9 & 4.1 & 8.1 \\
\hline $\begin{array}{l}\text { Low-level medium- } \\
\text { technology }\end{array}$ & 94.4 & 4.7 & 17.8 & 3.7 & 3.7 \\
\hline Low-tech & 80.4 & 3.6 & 28.6 & - & 3.6 \\
\hline
\end{tabular}

Source: National Statistical Service of Russian Federation.

We also note the high interest of foreign partners in cooperation in the production of leather, leather goods and footwear $(100.0 \%)$, the production of tobacco products $(66.7 \%)$. The interest of foreign partners in these activities once again underlines the earlier conclusions about the emerging trend of transfer of dirty production in developing countries and in Russia. In high-tech activities, the interest of foreign partners is associated with the production of pharmaceutical products $(20.0 \%)$. Among the medium-tech types of high-level production should be noted chemical production $(24.9 \%)$.

We note the high cooperative activity of organizations to produce pharmaceutical products. Organizations of this type of activity are actively copied not only with partners from the EU, but also from India and China (20.0\%), CIS countries (13.3\%). This fact may indicate more favorable conditions for cooperation provided by foreign countries and their interest in the joint development of new types of pharmaceutical products, due to the high resource base in this area preserved in Russia. It should also be noted the shift of interest of organizations in this type of activity towards foreign partners in comparison with partners of the CIS countries, which indicates the global competitiveness of products.

According to earlier studies (Arkhipova and Golichenko, 2007), foreign partners showed an increased interest in cooperation in such VD as the production of aircraft, including space, and in activities close to the extractive industries. Currently, in Russia, the focus of interest of foreign partners has shifted to the production of pharmaceutical products and remained unchanged in activities close to the extractive industries. As for the production of aircraft, including space vehicles, the cooperation activity of foreign partners in it in 2016 compared to the level of 2015, it fell more than 4 times and amounted to $3.0 \%$ for the EU and partner countries compared to $13.9 \%$, and with the US and Canada countries it was not implemented at all. The high interest of Russian partners in this TA testifies to its internal competitiveness. 
Interesting is the fact of the displacement of interest in cooperation, beginning in 2016, in the direction of scientific organizations and universities. While in 2014 the share of organizations involved in innovative cooperation with universities amounted to $5 \%$ of the total number of partnerships, in 2017 it already amounted to $28 \%$. This fact can be explained by the high scientific potential and good material and technical base concentrated in the leading Russian universities. Also, this type of cooperation provides access to new technologies on relatively favorable terms for most enterprises. The least interest for cooperation was demonstrated by the competitors of the industry $(6.5 \%)$ due to the spill-over effect, as well as consulting firms (11.1\%) (Figure 1).

Figure 1. Distribution of organizations involved in joint projects by type of partners, 2016, \% (GKS, 2016)

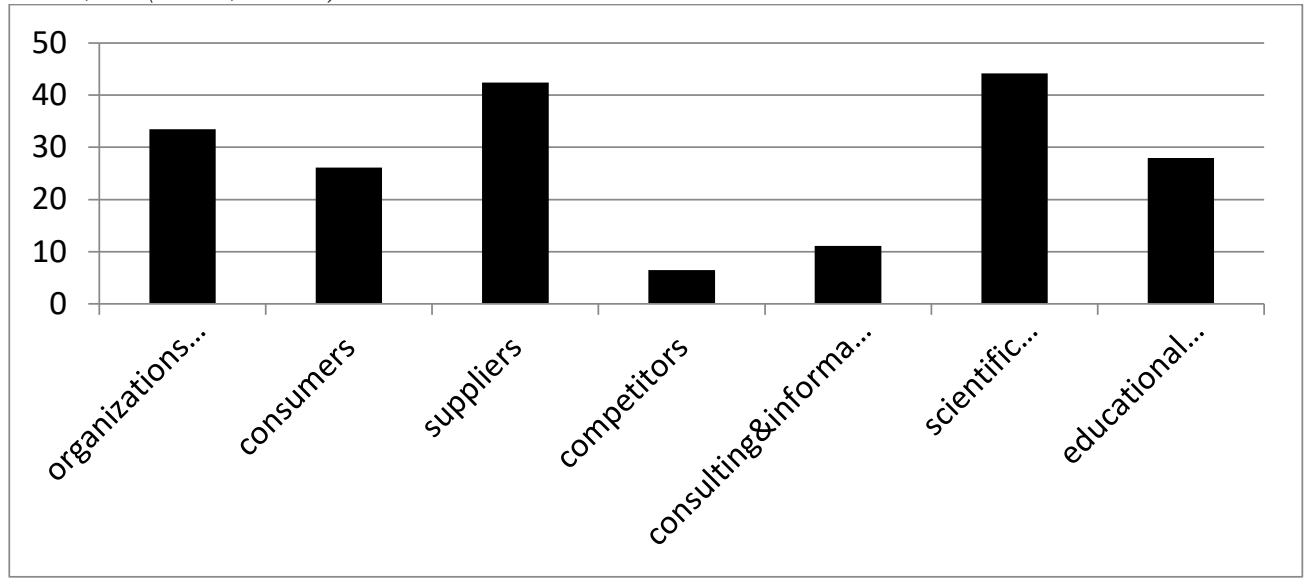

Leaders in the number of joint projects with scientific organizations are such TA, as the production of other vehicles (68.7\%), metallurgical production (67.6\%), pharmaceutical production $(66.7 \%)$, the production of coke and petroleum products $(66.7 \%)$, chemical production $(56.8 \%)$, the production of office equipment and computer equipment $(50.0 \%)$. The greatest interest in cooperation with higher education institutions is shown by the activities of metallurgical production $(67.6 \%)$, construction and repair of ships $(56.6 \%)$, leather production $(50.0 \%)$, aircraft production $(45.5 \%)$.

The study of the types of partners in the dynamics allows us to see that as partners of joint projects, the share of suppliers of equipment, raw materials and materials, as well as the share of consulting firms, has sharply decreased. The least popular in Russia are third-party consulting or information firms, the share of which among the partner organizations for joint innovation cooperation is only 2\%. For comparison, in 2005 and 2010 the share of suppliers in joint projects was the highest. All types of partnerships, especially with scientific organizations and educational institutions of higher education, are more characterized by cooperation within a specific project than by continuous cooperation. The exception is the ratio of the types of cooperation in cooperation with the group, which includes the organization, where the constant 
cooperation slightly exceeds the cooperation within a project. One-time or informal cooperation, which is not associated with any specific project, is used by Russian enterprises in all spheres of activity less often.

Studying the types of partners most actively in terms of scientific and technical cooperation, it should be noted that high-tech industries are seeking to create joint projects with scientific organizations and universities, especially in the field of pharmaceutical production, production of electronic components, measuring instruments, control, management and testing, production of aviation equipment (with educational institutions). Cooperation with suppliers is typical for TA office equipment and computer equipment (75\%), aircraft industry (42.4\%). Aircraft production shows a tendency to cooperate also with consumers of goods and services, consulting, information firms.

\section{Development of the Indicator of Cooperative Activity}

Russian regions are characterized by significant differences in the level of development of scientific and technical potential. In this regard, it is of interest to study the points of growth of regional cooperation activity. We propose a ranking of Russian regions by the level of cooperation activity on the basis of a specially developed latent indicator, which includes a wide range of indicators that allow to take into account various aspects of cooperation activity during the $R \& D$ in the regions of the Russian Federation. To solve this problem, based on the study of extensive theoretical materials, the following system of indicators was formed:

$\mathrm{X} 1$ - number of joint R\&D projects, units per thousand people;

$\mathrm{X} 2$ - number of joint projects by type of partners - scientific organizations, units per thousand people;

$\mathrm{X} 3$ - share of organizations involved in the development of joint R\&D projects, \%;

$\mathrm{X} 4$-number of granted patents for inventions, units per thousand people;

X5-number of patents granted for utility models, units per thousand people.

The creation of the latent indicator was carried out using the methods of dimension reduction the principal component method. Verification of basic assumptions, among which the Bartlett's test of sphericity and the Kaiser-Meyer-Olkin measure of sampling adequacy allowed us to make a conclusion of the possible use of selected methods for the sample of objects.

The implementation of the principal components' method allowed to reduce the dimension of the feature space and to single out one main component explaining $52.8 \%$ of the variance as shown in Table 3. 
Table 3. The Principal Component share of explained variance (authors' elaboration)

\begin{tabular}{|l|l|l|l|l|}
\hline \multirow{2}{*}{$\begin{array}{l}\text { Principal } \\
\text { Component }\end{array}$} & \multicolumn{4}{|l|}{ Initial eigenvalues and shares of variance explained } \\
\cline { 2 - 5 } & Eigenvalue & share of variance, \% & $\begin{array}{l}\text { cumulative share of } \\
\text { variance, \% }\end{array}$ \\
\hline 1 & 2.111 & 52.786 & 52.786 \\
2 & .938 & 23.450 & 76.236 \\
3 & .542 & 13.544 & 89.780 \\
4 & .409 & 10.220 & 100.000 & \\
\hline
\end{tabular}

According to the algorithm proposed in Ayvazyan (2001), the first component can be used to construct an integral indicator of regional cooperation activity. To be able to compare the levels of regional development, the estimates of the integral indicator were adjusted to the interval $[0,1]$ and ranked. The first and last ten regions are presented in Table 4.

Table 4. Unified values of the cooperative activity index for the first and last ten regions of the Russian Federation, 2016 (authors' elaboration)

\begin{tabular}{|l|l|l|l|}
\hline $\begin{array}{l}\text { The name of the region (the } \\
\text { last ten) }\end{array}$ & Index value & $\begin{array}{l}\text { The name of the region (the } \\
\text { first ten) }\end{array}$ & Index value \\
\hline Ingush Republic & 0 & Nizhny Novgorod Region & 0.4989 \\
\hline Republic of Kalmykia & 0.0024 & Novosibirsk Region & 0.5085 \\
\hline Adygeya Republic & 0.0079 & Sverdlovsk Region & 0.5133 \\
\hline Sakhalin Region & 0.0435 & Moscow Region & 0.5414 \\
\hline Pskov Region & 0.0500 & Republic of Tatarstan & 0.5468 \\
\hline Republic of Komi & 0.0622 & Tomsk Region & 0.6480 \\
\hline Republic of Chechnya & 0.0635 & Saint-Petersburg & 0.6785 \\
\hline Republic of Tuva & 0.0646 & Magadan Region & 0.7074 \\
\hline Altai Republic & 0.0669 & Kamchatka Territory & 0.7245 \\
\hline Zabaikalsky Krai & 0.0719 & City of Moscow & 1.0000 \\
\hline
\end{tabular}

Thus, the leading by the level of cooperation activity (the highest index of cooperation activity) regions of Russia were identified. Among them, Moscow, St. Petersburg, Tomsk, Novosibirsk region, the Republic of Tatarstan.

The five lagging regions in terms of the level of cooperation activity (the lowest index of cooperation activity) are the Republic of Ingushetia, the Republic of Kalmykia, the Republic of Adygea, Sakhalin and Pskov region.

\section{Identification of Scientific Regional Activity}

To test the hypothesis of the impact of scientific activity on cooperation in conducting R\&D stratify regions of Russia on the cost of scientific R\&D. At the same time, we will assume that the regions that invest significant resources in the development of science are also cooperative. 
The indicator y - the volume of internal expenditures on research and development per employee in rubles" (Sirotin and Arkhipova, 2013) was used for the study. Since the formation of the $y$ variable is due to the action of several multiplicative factors, it can be concluded that the distribution of a set of regions is a mixture of several distributions, and each component of this mixture follows lognormal distribution:

$f(\ln y)=\frac{1}{\sqrt{2 \pi} \sigma} e^{-\frac{(\ln y-\mu)^{2}}{2 \sigma^{2}}}$

where $\mu$ is the expected value of lny, and $\sigma$ is the standard deviation of lny.

It can also be assumed that the distribution of $\mathrm{y}$ consists of a weighted sum of $\mathrm{k}$ lognormal distributions of homogeneous groups of observations, that is:

$$
f(\ln y)=\sum_{i=1}^{k} q_{i} f\left(\ln y, \mu_{i}, \sigma_{i}\right)
$$

Based on a histogram of lny we assumed that initial distribution can be divided into three homogeneous groups. Presumably, the first stratum includes regions with the lowest level of resource potential, the second stratum is a middle group of regions, and the third one includes mainly agricultural regions and undeveloped northern regions of Russia.The estimation of the parameters of the mixture of distributions was carried out on the basis of the maximization of the likelihood logarithm:

$$
L=f\left(x_{1}, x_{2}, \ldots, x_{n} ; \mu_{1}, \ldots, \mu_{k}, \sigma_{1}, \ldots, \sigma_{k}, q_{1}, \ldots, q_{k}\right)=\prod_{j=1}^{n} f\left(x_{j} ; \mu_{1}, \ldots, \mu_{k}, \sigma_{1}, \ldots, \sigma_{k}, q_{1}, \ldots, q_{k}\right)
$$

where $\mu_{1}, \ldots, \mu_{k}, \sigma_{1}, \ldots, \sigma_{k}, q_{1}, \ldots, q_{k}$ are the required parameters of the mixture.

The most likelihood estimates of the parameters of the distribution mixture are presented in Table 5.

Table 5. The most likelihood estimates of the parameters of the mixture of distributions of the volume of internal research and development costs per capita (rubles per employee) in the regions of Russia, 2016 (authors' elaboration)

\begin{tabular}{|l|l|l|l|}
\hline \multirow{2}{*}{ Stratum number } & \multicolumn{3}{|l|}{ Parameter estimate } \\
\cline { 2 - 4 } & $\mu$ & $\sigma$ & $\mathrm{q}$ \\
\hline 1 & 5.91 & 0.58 & 0.41 \\
\hline 2 & 7.63 & 0.60 & 0.52 \\
\hline 3 & 9.76 & 0.31 & 0.07 \\
\hline
\end{tabular}


Analyzing the obtained coefficients, it can be noted that the largest share of observations belongs to the second stratum, $\mathrm{q}=0.52$; and the smallest to the third (scientifically active) stratum, the share of which is $7 \%$ of the total number of objects.

The group of regions with a high level of scientific potential includes 6 subjects of the Russian Federation, including Moscow, St. Petersburg, Moscow region, Nizhny Novgorod, Novosibirsk and Kaluga regions, and these results practically coincide with the result of ranking the regions according to the degree of cooperation activity obtained with the help of the author's summary indicator. The attractiveness of the Kaluga region in recent years is largely due to the location on its territory of the science-city Obninsk, as well as centers for the development of the automotive industry and pharmaceuticals. Those types of activities were noted as ones characterizing by high level of cooperation activity in the implementation of R\&D by Russian and foreign partners.

Thus, the empirical results of stratification of regions by splitting a mixture of probability distributions really confirmed the proposed assumption of a close relationship between scientific and cooperation activity. Regions that pay considerable attention to the implementation of R\&D show high cooperation activity with both Russian and foreign partners. It allows us to talk about these regions as points of growth of innovation development in modern Russia.

\section{Conclusion}

The study of the main trends in the development of scientific and technical cooperation in Russia by types of partners and cooperative relations between organizations showed that the majority of Russian enterprises are involved in the creation of joint projects in the framework of innovative cooperation with domestic organizations, focusing mainly on the domestic market, which is characterized by a low level of demand of the Russian consumer for the quality of the product (goods, services). This trend is quite stable and has recently intensified due to the unfavorable situation for entering the foreign economic market crisis and sanctions measures.

The study showed that the propensity to cooperate strongly depends on the type of activity. The general pattern is that the shorter the production cycle and/or more complex the production technology, the greater the desire for cooperation. Confirmation of this rule is the cooperation of firms in high-tech industries, in sectors with high intensity of R\&D (pharmaceuticals, production of medical priors, etc.). It is in these sectors of the economy that new technological achievements may appear, through scientific and technical partnership and integration of knowledge. Global points of growth of innovative activity in Russia are such economic activities as the production of pharmaceutical products, chemical production, as well as low-tech VD production of leather, leather goods and footwear, the production of tobacco products, which are directly aimed at the consumer. 
Local points of growth of innovative activity can be called VD production of coke and oil products, chemical production, production of office equipment and computer equipment. Organizations of the mentioned activities actively cooperate with scientific organizations and universities in carrying out research and development.

We can see the displacement of interest in cooperation, beginning in 2016, in the direction of scientific organizations and universities. This fact can be explained by the high scientific potential and good material and technical base concentrated in the leading Russian universities. Also, this type of cooperation provides access to new technologies on relatively favorable terms for most enterprises.

To study the impact of the resource base on the cooperative activity of the organization during the IIR was proposed the authors' composite indicator, which includes a wide range of indicators that consider various aspects of cooperative activity. Ranking of Russian regions by the level of cooperation activity allowed us to identify the leaders and outsiders of this process. Comparison of the results with the regional strata on the costs of $R \& D$ gave similar results, which led to the conclusion that the cooperative activity in the conduct of $R \& D$ is typical for those regions that pay significant attention to the development of science.

Among the leading regions it is worth noting Moscow, St. Petersburg, Tomsk, Moscow region, Novosibirsk region, Tatarstan Republic and Kaluga region. Five lagging regions in terms of the level of cooperation activity are Republic of Ingushetia, Republic of Kalmykia, Republic of Adygea, Sakhalin and Pskov region.

\section{References:}

Arkhipova, M., Golichenko, O. 2007. Cooperation activity in innovation processes in manufacturing industries in Russia. Economics of Contemporary Russia, 36(1), 121138.

Ayvazyan, S.A. 2001. Comparative analysis of integral characteristics of quality of life of the population of subjects of the Russian Federation. CEMI RAS, Moscow.

Ayvazyan, S.A. 2001. Cross-country analysis of integral categories of quality of life. CEMI RAS, Moscow.

Balassa, B. 1965. Trade Liberalization and Revealed Comparative Advantage. The Manchester School, 33, 99-123.

Chandra, V., Osorio-Rodarte, I., Primo-Braga, C.A. 2009. Korea and the BICs (Brazil, India and China): Catching-up Experiences. Innovation and Growth Chasing a Moving Frontier. The World Bank, Paris, 25-67.

Development Co-operation Report. 2018. OECD. Available online: https://www.oecdilibrary.org/development/development-co-operation-report-2018 dcr-2018-en.

Dynamizing National Innovation Systems. 2002. OECD Publications, Paris.

Freudenberg, M. 2003. Composite Indicators of Country Performance: A Critical Assessment. STI Working Paper, 16. 
Gamidullaeva, L. 2018. Towards Combining the Innovation Ecosystem Concept with Intermediary Approach to Regional Innovation Development. International Journal of Economics and Business Administration, 6(1), 39-53.

Geisler, E. 1995. Industry-university technology cooperation: a theory of interorganizational relationships. Technology Analysis \& Strategic Management, 7(2), 217-229.

Geisler, E., 1997. Inter-sector technology cooperation: hard myths, soft facts. Technovation, 17(6), 309-320.

GKS. 2016. Official data of Federal State Statistics Service of Russia. Available online: http://www.gks.ru.

Gumpert, M. 2019. Multidimensional Core-peripheral Model. International Journal of Economics and Business Administration, 7(1), 192-208.

Nagimov, A.R., Akhmetshin, E.M., Slanov, V.P., Shpakova, R.N., Solomonov, M.P. \& Il'yaschenko, D.P. 2018. Foresight technologies in the formation of a sustainable regional development strategy. European Research Studies Journal, 21(2), 741-752.

Oslo Manual. 2005. Guidelines for Collecting and Interpreting Innovation Data. OECD and Eurostat.

Ramani, S.V. 2000. Technology cooperation between firms of developed and less-developed countries. Economics Letters, Elsevier, 68(2), 203-209.

Science and Technology Indicators in the Russian Federation. 2018. HSE Data Books. Available online: https://www.hse.ru/primarydata/ii2018.

Sirotin, V., Arkhipova, M. 2013. Crisp and Fuzzy Classification in Social and Economic Research. MESI, Moscow.

Strategic public/private partnerships. 2014. Science, Technology and Industry Outlook, OECD Publishing, Paris.

Utami, C.W., Ferdiansah, M. 2017. Development of knowledge management model in establishing innovation and company performance in UMKM/SME in Indonesia. European Research Studies Journal, 20(4), 655-665. 